Gut, 1984, 25, 1268-1270

\title{
Intracellular electrical activity in circular muscle of canine colon
}

\author{
M M CHAMBERS, Y J KINGMA, AND K L BOWES \\ From the Departments of Surgery and Electrical Engineering, University of Alberta, Edmonton, Alberta, \\ Canada
}

SUMMARY In vivo and extracellular in vitro studies of colon muscle have led to a great deal of disagreement on the characteristics of slow wave activity. As intracellular recordings of electrical activity in single cells give clear records which are easier to analyse, we used this method to study the slow wave activity of the circular muscle of three different parts of the canine colon. Mucosa was removed from segments of proximal, mid and distal canine colon and specimens from each segment were mounted in an organ bath perfused with oxygenated Krebs' solution. Membrane potential, amplitude and frequency of slow waves were measured using intracellular electrodes. Slow wave activity was present at a single, continuous frequency of $4-6 \mathrm{cpm}$ in the circular muscle at all the sites studied in canine colon. There was no significant frequency gradient along the colon: the membrane potential and amplitude of slow waves did not differ significantly in the three parts of the colon.

The characteristics of slow wave activity in colon muscle remain controversial. In vivo studies in human and dog colon ${ }^{12}$ have shown gradients of slow wave activity along the colon, but these have not been confirmed in in vitro, extracellular studies. ${ }^{34}$ In vivo studies of human and dog colon have shown that slow wave activity is present intermittently at two or more frequencies, ${ }^{1} 256$ but in vitro extracellular studies in cat, dog, and human colon have suggested the presence of one, fundamental, continuous slow wave frequency. ${ }^{3} 78$ It has been suggested that higher frequencies are caused by simultaneous recording from two or more poorly coupled oscillatory regions or to harmonics of the fundamental frequency. ${ }^{3} 8$

To obtain definitive data on the slow wave activity of the circular muscle of canine colon, we have used intracellular electrodes to study the electrical events in single circular muscle cells in tissue samples taken from proximal, mid and distal canine colon.

\section{Methods}

DOGS

Segments were removed from each of the proximal, mid and distal colon in 29 healthy, anaesthetised

Address for correspondence: M M Chambers, Department of Surgery, 11-105 Clinical Sciences Building, University of Alberta, Edmonton, Alberta, Canada T6G 2G3.

Received for publication 10 February 1984 dogs, and immediately placed in oxygenated Krebs' solution. The blood supply to the segments was maintained until the moment of excision.

The mucosa was removed from each segment by sharp dissection and each specimen, measuring $0.5 \times 0.2 \times 0.1 \mathrm{~cm}$, was pinned onto the silicone rubber base of an organ bath which was constantly perfused with warmed, oxygenated Krebs' solution. The temperature was maintained at $37 \cdot 5 \pm 0 \cdot 5^{\circ} \mathrm{C}$. The specimens were mounted with the circular muscle uppermost and the submucosa intact.

Single muscle cells were penetrated with glass microelectrodes having an impedance of $40-100 \mathrm{M} \Omega$ (tip diameter of $0.5-0.2 \mu \mathrm{m}$ ) filled with $3 \mathrm{M} \mathrm{KCl}$. The signals were measured with a high input impedance amplifier (WPI Instruments Inc, Model K5-700), displayed on an oscilloscope (Hewlett Packard 1741A) and recorded on a Moseley Autograf Model 680 pen recorder.

Penetrations were considered acceptable when a sharp voltage drop, followed by a steady resting potential lasting for several minutes was seen.

As satisfactory recordings were not always obtained from a complete set of the three specimens of a series, statistical analysis was carried out using the Students' $t$ test for unpaired data.

\section{Results}

Successful penetrations, with the microelectrode 
remaining in the cell up to one hour, were obtained in 29 segments of proximal, 24 of mid, and 24 of distal colon. Successful penetrations were far more difficult to achieve in the circular muscle cells of the distal colon than in the proximal and mid colon. Penetrations in the distal colon were often incomplete, giving rise to less negative membrane potentials or, once in the cell, the electrode only remained in for a few slow wave cycles. Whenever a muscle cell was successfully penetrated, continuous slow wave activity was always seen at a single frequency of 4-6 cpm in all regions.

The results of the penetrations are presented in the Table. Statistical analysis was performed using the Students' $t$ test for unpaired data. We found no significant difference between the membrane potential, slow wave amplitude or frequency of slow wave activity in the specimens taken from the three parts of the colon. Typically, the resting membrane potential was approximately $-70 \mathrm{mV}$; the spontaneous slow wave caused a depolarisation to $-33 \mathrm{mV}$, which was followed by a slight plateau potential and then a return to the resting potential (Figure).

\section{Discussion}

Extensive studies on the electrical activity of gastric muscles, ${ }^{9-11}$ using electrodes placed at multiple sites, have helped to elucidate the mechanisms of gastric contraction. Similar studies both in vivo and in vitro in the colon have produced contradictory results.

Intracellular recordings of electrical activity in single muscle cells were made in an attempt to resolve these differences. This method of measurement gives much cleaner records which are very simple to analyse, and additional information on the resting potential and amplitude of slow waves, which cannot be obtained from extracellular measurements.

The present study showed that whenever a successful penetration was achieved, slow waves were continuously present at a single frequency of

Table Characteristics of slow wave activity in circular muscle of canine colon

\begin{tabular}{llll}
\hline & \multicolumn{3}{l}{$($ Mean \pm SD) } \\
\cline { 2 - 4 } & $\begin{array}{l}\text { Proximal } \\
\text { colon }\end{array}$ & $\begin{array}{l}\text { Mid } \\
\text { colon }\end{array}$ & \multicolumn{1}{l}{$\begin{array}{l}\text { Distal } \\
\text { colon }\end{array}$} \\
\hline No & 29 & 24 & \multicolumn{1}{l}{24} \\
Membrane potential $(-\mathrm{mV})$ & $64 \cdot 6 \pm 7 \cdot 50$ & $60 \cdot 6 \pm 9 \cdot 6$ & $58 \cdot 8 \pm 9 \cdot 4$ \\
Slow wave amplitude (mV) & $26 \cdot 7 \pm 6 \cdot 1$ & $25 \cdot 7 \pm 7 \cdot 5$ & $24 \cdot 9 \pm 7 \cdot 1$ \\
Rate (cpm) & $5 \cdot 3 \pm 0 \cdot 9$ & $5 \cdot 2 \pm 0 \cdot 9$ & $5 \cdot 1 \pm 0 \cdot 8$ \\
\hline
\end{tabular}
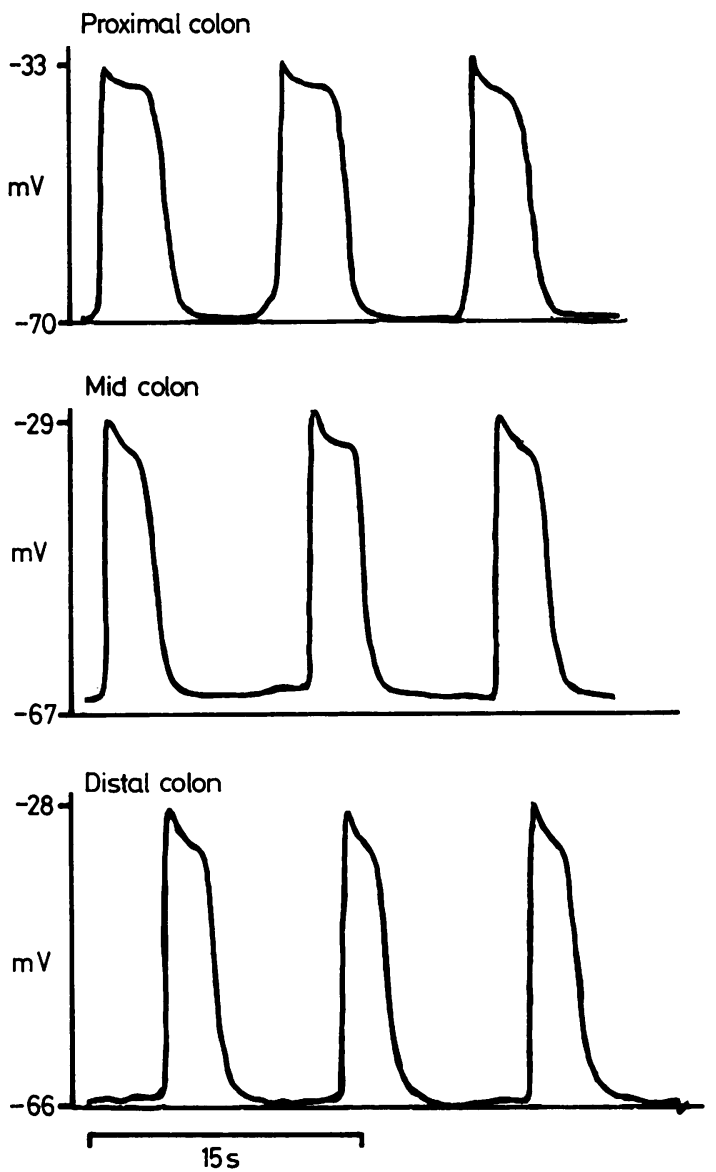

Figure Comparison of slow wave activity in circular muscle of proximal, mid and distal canine colon, as measured with intracellular electrodes.

4-6 cpm in all parts of the colon. This confirms our previous results using extracellular electrodes ${ }^{4}$ which showed a single, continuous, fundamental frequency of slow waves: the higher frequencies occasionally seen in extracellular studies and attributed to second and third harmonics of the fundamental frequency were not seen in these intracellular studies. This frequency of slow waves did not differ significantly in different parts of the colon.

The membrane potential and slow wave amplitude showed no significant differences in the three parts of the colon. The only aspect of measurement which differed between the regions, was the degree of difficulty in making successful penetrations; the distal colon was far more difficult than the proximal or mid regions. Although mechanical activity was not measured in this study, 
it is possible that stronger contractile activity in the distal colon accounts for these difficulties. The resting potential and frequency of slow wave activity in the distal colon agrees with those of a previous study ${ }^{12}$ but we found the amplitude of the slow wave to be approximately twice that seen previously. In our experience such a low amplitude indicates an incomplete cellular penetration.

Intracellular resting membrane potentials have been measured in all regions of the canine stomach. ${ }^{13} \mathrm{~A}$ definite gradient of resting membrane potential was seen, becoming more negative as the recording site was moved from the fundus to the antrum. This change was accompanied by an increase in spontaneous electrical activity. Our demonstration of a constant resting potential throughout the colon shows that the basic electrical properties are quite different in the two organs and therefore suggests that the electrical control of contraction in the colon operates by different mechanisms than in the stomach. This is further supported by a study in which a marked frequency gradient was found along the axis of the stomach, ${ }^{10}$ in contrast to our findings of no frequency gradient along the colon.

While this study does not resolve the question of the extent to which contractile activity is governed by electrical activity in the intact colon, it does better define the parameters describing the electrical activity in single cells in the canine colon.

\section{References}

1 Taylor I, Duthie HL, Smallwood R, Linkens D. Large bowel myoelectrical activity in man. Gut 1975; 16: 808-14.

2 Vanasin B, Ustach TJ, Schuster MM. Electrical and motor activity of human and dog colon in vitro. Johns Hopkins Med J 1974; 134: 201-10.

3 Chambers MM, Bowes KL, Kingma YJ, Bannister C, Cote KR. In vitro electrical activity in human colon. Gastroenterology 1981; 81: 502-8.

4 Shearin NL, Bowes KL, Kingma YJ. In vitro electrical activity in canine colon. Gut 1979; 20: 780-6.

5 Sarna SK Bardakjian BL, Waterfall WE, Lind JF. Human colonic electrical control activity (ECA). Gastroenterology 1980; 78: 1526-36.

6 Snape WJ, Carlson GM, Cohen S. Colonic myoelectric activity in the irritable bowel syndrome. Gastroenterology 1976; 70: 326-30.

7 Christensen J, Caprilli R, Lund G. Electrical slow waves in circular muscle of the cat colon. Am J Physiol 1969; 217: 771-6.

8 Bowes KL, Shearin NL, Kingma YJ, Koles ZJ. Frequency analysis of electrical activity in dog colon. In: Proceedings of the 6th international symposium of gastrointestinal motility, Edinburgh, Scotland. Lancaster: MTP Press, 1978: 251-69.

9 Kelly KA, Code CF, Elveback LR. Patterns of canine gastric activity. Am J Physiol 1969; 217: 461-70.

10 Sarna SK, Daniel EE, Kingma YJ. Simulation of the electrical control activity of the stomach by an array of relaxation oscillators. Am J Dig Dis 1972; 17: 299-310.

11 Weber J, Kohatou S. Pacemaker localization and electrical conduction patterns in the canine stomach. Gastroenterology 1970; 59: 717-26.

12 Hara A, Szurszewski JH. Intracellular electrical activity from the circular muscle of the canine distal colon. Fed Proc 1981; 40: 577.

13 Szurszewski JH. Electrical basis for gastrointestinal motility. In: Johnson LR, ed. Physiology of the gastrointestinal tract. New York: Raven Press, 1981: 1435-66. 